\title{
Cerebral Microbleeds: Histopathological Correlation of Neuroimaging
}

\author{
A. Shoamanesh ${ }^{\mathrm{a}}$ C.S. Kwok ${ }^{\mathrm{c}}$ O. Benavente $\mathrm{B}^{\mathrm{a}, \mathrm{b}}$ \\ a Division of Neurology, Department of Medicine, and ${ }^{\mathrm{b}}$ Brain Research Center, UBC Hospital, University of British \\ Columbia, Vancouver, B.C., Canada; 'SChool of Medicine, Health Policy and Practice, Health and Social Sciences \\ Research Institute, Faculty of Health, University of East Anglia, Norwich, UK
}

\section{Key Words}

Microbleeds $\cdot$ Microhaemorrhage $\cdot$ Microhemorrhage $\cdot$

Pathology $\cdot$ Histology $\cdot$ Histopathology

\begin{abstract}
Background: In recent years, there has been a growing interest in cerebral microbleeds (CMBs) and their role in cerebrovascular disease. A few studies have investigated the histopathological correlation between CMBs and neuroimaging findings. We conducted a systematic review in an attempt to characterize the pathological and radiological correlation. Methods: A systematic literature search was conducted for studies in which CMBs were characterized histopathologically and correlated with MRI findings. Results: Five studies met the inclusion criteria, with a total of 18 patients. Hemosiderin deposition was reported in 42 CMBs (49\%), while 16 CMBs (19\%) were described as old hematomas which stained for iron, 13 (15\%) had no associated specific pathology, 11 (13\%) contained intact erythrocytes, $1(1 \%)$ was due to vascular pseudocalcification, 1 (1\%) was a microaneurysm and $1(1 \%)$ was a distended dissected vessel. Lipofibrohyalinosis was the most prominent associated vascular finding. Amyloid angiopathy was present primarily in patients with dementia. Conclusions: Although histopathological associations have been observed using MRI in patients with CMBs, the findings have yet to be validated and further research is warranted.
\end{abstract}

Copyright $\odot 2011$ S. Karger AG, Basel

\section{KARGER}

Fax +4161306 1234 E-Mail karger@karger.ch www.karger.com

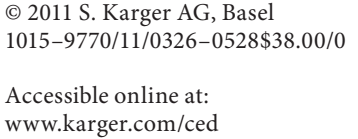

\section{Introduction}

Cerebral microbleeds (CMBs) are defined as small round hypointense foci on $\mathrm{T} 2$ *-weighted gradient-recalled echo (GRE) magnetic resonance imaging (MRI) and are believed to represent hemosiderin deposits that can remain in macrophages for years following a microhemorrhage. In recent years, there has been an exponentially growing interest in determining the clinical significance of CMBs. Yet, there have only been a few studies investigating the histopathological correlation of CMBs as defined by neuroimaging. Histopathological confirmation of CMBs seen on neuroimaging is important because there are a number of CMB mimics. It is thus prudent to ensure that the contemporary studies on CMBs, which are being performed under the assumption that the hypointensities seen on MRI represent areas of old microhemorrhage, are not done so in vain.

Recently, Gouw et al. [1] published a systematic review of the histopathology of MRI findings in small vessel disease that comments on CMBs. However, as CMBs were not the main focus of their paper, there has yet to be a review solely on the histopathology of CMBs. We conducted a systematic review focusing exclusively on the relationship between CMBs observed on neuroimaging and correlated analysis of histopathological samples, resulting in a more detailed analysis of the topic.

Ashkan Shoamanesh, MD

Division of Neurology, Department of Medicine

University of British Columbia, 1103-1068 West Broadway Ave

Vancouver, BC V6H 0A7 (Canada)

Tel. +1 778847 6338,E-Mail ashkan.sho@gmail.com 
Fig. 1. Flow diagram of our literature search and study selection. CCRT $=$ Cochrane Central Register of Controlled Trials; ESC = European Stroke Conference; ISC = International Stroke Conference; AANAM = American Academy of Neurology Annual Meeting.

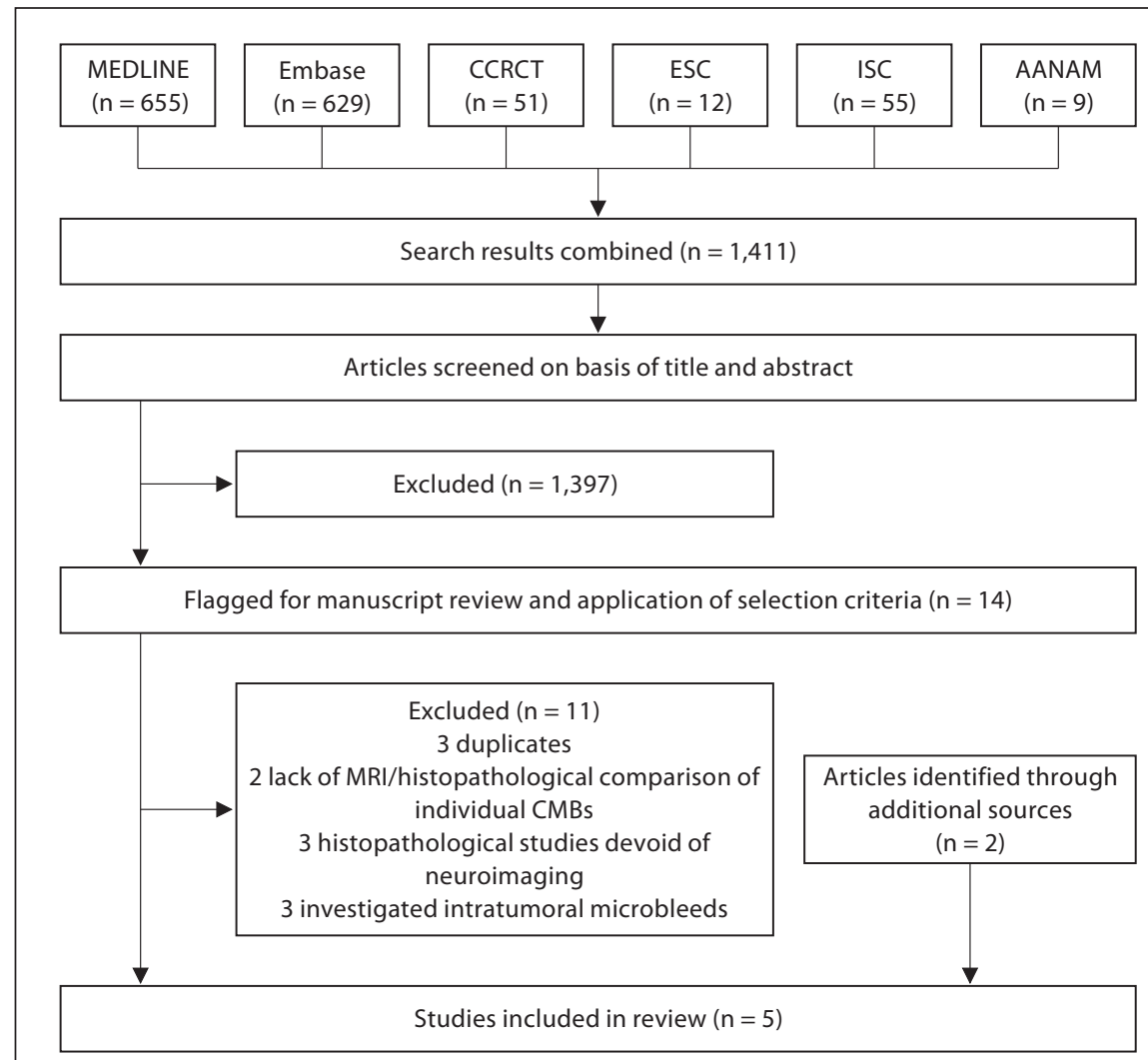

\section{Methods}

Wherever applicable, we adhered to previously published guidelines on conducting systematic reviews of diagnostic studies [2]. A systematic literature search was performed by one of the authors (C.S.K.). A comprehensive search strategy is provided within the Appendix.

One reviewer (A.S.) scanned all titles and abstracts for studies that met the predetermined selection criteria and extracted the relevant data (fig. 1). Human studies in which CMBs, as defined by T2*-weighted GRE MRI, were investigated by histopathology and which provided a direct comparison of MRI and histopathology for individual lesions were eligible. Those studies investigating CMBs $>10 \mathrm{~mm}$ in diameter, intratumoral microbleeds or patients with head trauma were excluded. The accuracy of the extracted data was confirmed independently by another reviewer (O.B.).

Histopathological evidence of a previous microbleed was defined as any site that contained hemosiderin-laden macrophages, hemosiderin deposits, erythrocytes or hematoma formation.

\section{Results}

We identified 5 studies that met our predetermined criteria. The first and largest study, published by Fazekas et al. [3] in 1999, was the only study that comments on the
Table 1. Histopathological stains used in reviewed studies

\begin{tabular}{ll}
\hline Study & Stains \\
\hline $\begin{array}{l}\text { Fazekas } \\
\text { et al., 1999 [3] }\end{array}$ & $\begin{array}{l}\text { hematoxylin and eosin, Masson trichrome, } \\
\text { Kluver-Barrera technique for myelin, Congo red } \\
\text { for amyloid and with iron }\end{array}$ \\
\hline $\begin{array}{l}\text { Tanaka } \\
\text { et al., 1999 [4] }\end{array}$ & Kluver-Barrera technique for myelin \\
\hline $\begin{array}{l}\text { Kikuta } \\
\text { et al., 2007 [5] }\end{array}$ & $\begin{array}{l}\text { immunostaining with antibodies against human } \\
\text { factor VIII and human } \alpha \text {-smooth muscle actin }\end{array}$ \\
\hline $\begin{array}{l}\text { Tatsumi } \\
\text { et al., 2008 [6] }\end{array}$ & hematoxylin and eosin, Prussian blue for iron \\
\hline $\begin{array}{l}\text { Schrag } \\
\text { et al., 2009 [7] }\end{array}$ & hematoxylin and eosin, Prussian blue for iron
\end{tabular}

blinding of investigators conducting histopathological analysis to neuroimaging findings in their methodology.

Although histopathological stains were generally homogenous amongst the studies (table 1), MRI parameters varied greatly and are summarized in table 2 [3-7]. The 
Table 2. MRI parameters

\begin{tabular}{|c|c|c|c|c|c|c|c|}
\hline Study & $\begin{array}{l}\text { Timing of MRI/tissue preparation } \\
\text { prior to imaging }\end{array}$ & $\begin{array}{l}\text { Field } \\
\text { strength T }\end{array}$ & Sequence & $\begin{array}{l}\text { Slice } \\
\text { thickness, mm }\end{array}$ & $\mathrm{TR}, \mathrm{ms}$ & $\mathrm{TE}, \mathrm{ms}$ & $\begin{array}{l}\text { Flip angle } \\
\text { degrees }\end{array}$ \\
\hline $\begin{array}{l}\text { Fazekas } \\
\text { et al., } 1999[3]\end{array}$ & $\begin{array}{l}\text { postmortem/ } \\
\text { fixed in formalin }\end{array}$ & 1.5 & GRE & 5 & $550-650$ & 15 & 25 \\
\hline $\begin{array}{l}\text { Tanaka } \\
\text { et al., } 1999[4]\end{array}$ & antemortem/NA & 1 & GRE & $\begin{array}{l}\text { not } \\
\text { specified }\end{array}$ & $2,178-2,190$ & $36-37$ & 25 \\
\hline $\begin{array}{l}\text { Kikuta } \\
\text { et al., } 2007 \text { [5] }\end{array}$ & antemortem/NA & 3 & $\begin{array}{l}\text { T2-weighted } \\
\text { (not specified) }\end{array}$ & $\begin{array}{l}\text { not } \\
\text { specified }\end{array}$ & $\begin{array}{l}\text { not } \\
\text { specified }\end{array}$ & $\begin{array}{l}\text { not } \\
\text { specified }\end{array}$ & $\begin{array}{l}\text { not } \\
\text { specified }\end{array}$ \\
\hline $\begin{array}{l}\text { Tatsumi } \\
\text { et al., } 2008 \text { [6] }\end{array}$ & $\begin{array}{l}\text { postmortem/fixed in formalin, } \\
\text { imaged in water }\end{array}$ & 1.5 & GRE & 3 & 700 & 17 & 20 \\
\hline $\begin{array}{l}\text { Schrag } \\
\text { et al., } 2009 \text { [7] }\end{array}$ & $\begin{array}{l}\text { postmortem/fixed in formalin, } \\
\text { imaged embedded in } 4 \% \text { agarose } \\
\text { gel }\end{array}$ & 3 & GRE (SWI) & 2 & 30 & 20 & 15 \\
\hline
\end{tabular}

NA $=$ Not applicable.

upper limit of CMB diameter was defined as $5 \mathrm{~mm}$ in two studies [3, 6], $5.7 \mathrm{~mm}$ in one [7] and $10 \mathrm{~mm}$ in another [5]. Tanaka et al. [4] did not define a specific parameter but did comment that the majority of CMBs had a diameter within the range of $2-5 \mathrm{~mm}$. In total, the studies included 26 patients. Four patients in the study by Fazekas et al. [3] and 4 in that by Schrag et al. [7] did not have any CMBs visualized on neuroimaging [3, 7]. Moreover, 2 of the CMBs in the study by Kikuta et al. [5] were never investigated by histopathology. Thus, the association between CMBs seen on imaging and their histopathology has been investigated in a total of 18 patients, encompassing 85 lesions.

The mean age of the patients was 73 years, and 56\% were men (table 3). Hypertension was present in $44 \%$, in whom $82.5 \%$ (33/40) of CMBs were located in the subcortical gray matter, brainstem or cerebellum. In contrast, amongst nonhypertensives $(\mathrm{n}=10), 6$ of whom had documented dementia, $76.6 \%$ (36/47) of lesions were corticosubcortical.

\section{Histopathology of CMBs}

Fazekas et al. [3] demonstrated that in 7 patients with previous intracerebral hemorrhage (ICH), 21 out of 34 $\mathrm{CMBs}$ contained hemosiderin-laden macrophages (table 4). These were often perivascular. In the remaining 13 CMBs, no specific pathology was found. In the 3 different cases with various causes of death investigated by Tanaka et al. [4], all 3 CMBs demonstrated hemosiderin deposits in the perivascular space. However, one lesion also had an associated organized pseudoaneurysm. An autopsy study of a 97-year-old woman who died following an ischemic stroke demonstrated hemosiderin-laden macrophages in 8 of 9 CMBs [6]. The underlying pathology of the remaining lesion was vascular pseudocalcification. One $\mathrm{CMB}$ resected from the right frontal operculum in a 65 -yearold male with presumed moyamoya disease during a superficial temporal artery-middle cerebral artery bypass procedure revealed an encapsulated hematoma containing erythrocyte deposition [5]. There was no mention of the presence or absence of hemosiderin.

The 6 cases with a diagnosis of Alzheimer's disease [7] had $38 \mathrm{CMBs}$ visualized on susceptibility-weighted imaging (SWI). Sixteen of these lesions were described as old hematomas which stained for iron, 10 lesions contained intact erythrocytes, 7 revealed cavitary lesions which were associated with a gliotic capsule containing hemosiderin granules and hemosiderin-laden macrophages, 3 contained hemosiderin granules and hematoidin deposition, 1 was a microaneurysm and another a dissection in the wall of a grossly distended vessel. The cavitary lesions were occasionally associated with a characteristic hyperintense halo surrounding the hypodensity on SWI, particularly in the deep white matter.

\section{Vascular and Other Associated Pathology}

Lipofibrohyalinosis seems to be the most prominent vascular finding in relation to CMBs and was present in all of the patients investigated by Fazekas et al. [3]. Two of their patients also displayed moderate to severe amyloid 
Table 3. Patient demographics and MRI findings

\begin{tabular}{|c|c|c|c|c|c|c|c|c|c|c|}
\hline Case & $\begin{array}{l}\text { Age/ } \\
\operatorname{sex}\end{array}$ & $\begin{array}{l}\text { Patient population } \\
\text { and/or cause of death }\end{array}$ & HTN & $\begin{array}{l}\text { Previous } \\
\text { ICH }\end{array}$ & Lacunae & $\begin{array}{l}\text { Cortical } \\
\text { strokes }\end{array}$ & $\begin{array}{l}\text { White matter } \\
\text { hyperintensity } \\
\text { grade }\end{array}$ & $\begin{array}{l}\text { Cortico- } \\
\text { subcortical } \\
\text { CMBs }\end{array}$ & $\begin{array}{l}\text { Basal ganglia/ } \\
\text { thalamic } \\
\text { CMBs }\end{array}$ & $\begin{array}{l}\text { Infra- } \\
\text { tentorial } \\
\text { CMBs }\end{array}$ \\
\hline $1[3]$ & $64 / \mathrm{M}$ & $\mathrm{ICH}$ & - & lobar & - & - & $0^{\mathrm{a}}$ & 2 & 0 & 0 \\
\hline $2[3]$ & $74 / \mathrm{M}$ & ICH & + & $\begin{array}{l}\text { basal ganglia, } \\
\text { thalamus }\end{array}$ & ++ & - & $3^{\mathrm{a}}$ & 3 & 4 & 0 \\
\hline $3[3]$ & $74 / \mathrm{M}$ & $\mathrm{ICH}$ & + & lobar & ++ & + & $2^{\mathrm{a}}$ & 1 & 4 & 2 \\
\hline $4[3]$ & $84 / \mathrm{F}$ & $\mathrm{ICH}$ & + & brainstem & + & - & $0^{\mathrm{a}}$ & 0 & 7 & 5 \\
\hline $5[3]$ & $71 / \mathrm{M}$ & $\mathrm{ICH}$ & - & lobar & - & - & $2^{\mathrm{a}}$ & 1 & 1 & 1 \\
\hline $6[3]$ & $74 / \mathrm{F}$ & $\mathrm{ICH}$ & + & lobar & + & - & $2^{\mathrm{a}}$ & 1 & 0 & 0 \\
\hline $7[3]$ & $58 / \mathrm{M}$ & $\mathrm{ICH}$ & + & thalamus & ++ & - & $3^{a}$ & 1 & 1 & 0 \\
\hline $8[4]$ & $66 / \mathrm{F}$ & B cell lymphoma, pneumonia & - & - & - & - & NA & 1 & 0 & 0 \\
\hline $9[4]$ & $67 / \mathrm{M}$ & HTLVI myelopathy, pneumonia & + & - & ++ & - & NA & 0 & 1 & 0 \\
\hline $10[4]$ & $50 / \mathrm{M}$ & SAH & + & - & + & - & $\mathrm{NA}$ & 0 & 1 & 0 \\
\hline $11[5]$ & $65 / \mathrm{M}$ & moyamoya disease & - & - & - & - & NA & 3 & 0 & 0 \\
\hline $12[6]$ & $97 / \mathrm{F}$ & ischemic stroke, gastric cancer & + & - & ++ & + & mild $^{\mathrm{b}}$ & 1 & 5 & 3 \\
\hline $13[7]$ & $61 / \mathrm{M}$ & $\begin{array}{l}\text { dementia ( } 2 \text { years/rapidly progressive), } \\
\text { malnutrition }\end{array}$ & - & NA & NA & NA & NA & 5 & 0 & 0 \\
\hline $14[7]$ & $85 / \mathrm{F}$ & dementia (slowly progressive), CAD & - & NA & NA & NA & NA & 4 & 1 & 0 \\
\hline $15[7]$ & $73 / \mathrm{F}$ & dementia (severe) & - & NA & NA & NA & NA & 3 & 0 & 0 \\
\hline $16[7]$ & $90 / \mathrm{M}$ & $\begin{array}{l}\text { dementia (severe/slowly progressive), } \\
\text { pneumonia }\end{array}$ & - & NA & NA & $\mathrm{NA}$ & NA & 4 & 1 & 0 \\
\hline 17 [7] & $74 / \mathrm{F}$ & dementia (severe/slowly progressive), ICH & - & lobar & NA & NA & NA & 9 & 2 & 0 \\
\hline $18[7]$ & $86 / \mathrm{F}$ & $\begin{array}{l}\text { dementia ( } 8 \text { years/slowly progressive), } \\
\text { pneumonia }\end{array}$ & - & NA & NA & NA & NA & 4 & 1 & 4 \\
\hline
\end{tabular}

HTN = Hypertension; HTLVI = human T lymphocytic virus I; SAH = subarachnoid hemorrhage; CAD = coronary artery disease; NA = not assessed or not provided; + designates presence of; - designates absence of; ++ designates multiple $(>1)$.

${ }^{\text {a }}$ White matter hyperintensity grade as per Fazekas et al. [8] on postmortem MRI.

${ }^{\mathrm{b}}$ White matter hyperintensity noted on antemortem MRI.

Table 4. Histopathological correlation of neuroimaging

\begin{tabular}{|c|c|c|c|c|}
\hline Study & $\begin{array}{l}\text { CMBs } \\
\text { investigated }\end{array}$ & Histopathology of CMBs (n) & Associated vascular pathology & 'Blooming effect' \\
\hline $\begin{array}{l}\text { Fazekas } \\
\text { et al., } 1999 \text { [3] }\end{array}$ & 34 & $\begin{array}{l}\text { hemosiderin-laden macrophages (21), } \\
\text { no specific pathology (13) }\end{array}$ & $\begin{array}{l}\text { lipofibrohyalinosis, } \\
\text { amyloid angiopathy }\end{array}$ & NA \\
\hline $\begin{array}{l}\text { Tanaka } \\
\text { et al., } 1999[4]\end{array}$ & 3 & $\begin{array}{l}\text { hemosiderin deposits ( } 3 \text { ), } \\
\text { organized pseudoaneurysm (1) }\end{array}$ & arteriosclerotic microvessels & NA \\
\hline $\begin{array}{l}\text { Kikuta } \\
\text { et al., } 2007 \text { [5] }\end{array}$ & 1 & $\begin{array}{l}\text { encapsulated hematoma containing } \\
\text { erythrocyte deposition (1) }\end{array}$ & $\begin{array}{l}\text { arterioles with disrupted internal } \\
\text { elastic lamina }\end{array}$ & NA \\
\hline $\begin{array}{l}\text { Tatsumi } \\
\text { et al., } 2008[6]\end{array}$ & 9 & $\begin{array}{l}\text { hemosiderin-laden macrophages (8), } \\
\text { vascular pseudocalcification (1) }\end{array}$ & $\begin{array}{l}\text { lipohyalinosis, microaneurysm } \\
\text { formation }\end{array}$ & insignificant \\
\hline $\begin{array}{l}\text { Schrag } \\
\text { et al., } 2009[7]\end{array}$ & 38 & $\begin{array}{l}\text { old hematomas which stained for iron (16), } \\
\text { intact erythrocytes (10), } \\
\text { cavitary lesions with a gliotic capsule containing } \\
\text { hemosiderin granules and hemosiderin-laden } \\
\text { macrophages (7), hemosiderin granules and } \\
\text { hematoidin deposition (3), microaneurysm (1), } \\
\text { dissection in the wall of a distended vessel (1) }\end{array}$ & $\begin{array}{l}\text { amyloid angiopathy, } \\
\text { microaneurysm formation }\end{array}$ & $\begin{array}{l}1.57 \pm 0.75 \text { times larger, } \\
\text { greatest in smaller CMBs, } \\
\text { maximum magnitude of } 3\end{array}$ \\
\hline
\end{tabular}

$\mathrm{NA}=$ Not assessed 
angiopathy. Case 1 (table 3) was a nonhypertensive patient who had only experienced lobar ICHs and corticosubcortical CMBs. The other patient (case 2) was hypertensive and had also experienced a deep gray matter $\mathrm{ICH}$ and deep gray matter CMBs, in addition to cortico-subcortical ones. All 3 patients investigated by Tanaka et al. [4] were noted to have arteriosclerotic microvessels. The 97-year-old woman studied by Tatsumi et al. [6] displayed lipohyalinosis and microaneurysm formation. However, Schrag et al. [7] found most lesions in demented patients to contain evidence of cerebral amyloid angiopathy with vessel wall thickening, $\beta$-amyloid replacement of vascular smooth muscle and microaneurysms. The CMB in the patient with moyamoya disease contained arterioles with a disrupted internal elastic lamina.

Varying degrees of tissue rarefaction and gliosis, as well as lacunar infarction and a cribriform state of the basal ganglia, were observed in these studies [3-7].

\section{'Blooming Effect'}

The 'blooming effect', where MRI overestimates the diameter of a microbleed, was described in two studies (table 4). When using SWI [repetition time (TR)/echo time (TE): $30 / 20 \mathrm{~ms}$, flip angle $15^{\circ}$ ], CMBs were $1.57 \pm$ 0.75 times larger than their corresponding lesion on pathology [7]. The magnitude of 'blooming' was greater for smaller lesions. In contrast, Tatsumi et al. [6] found that the size of CMBs on GRE MRI (TR/TE: 700/17 ms, flip angle $20^{\circ}$ ) and corresponding hemosiderin deposits were roughly similar.

\section{Discussion}

Our review of the literature suggests that there is a strong association between CMBs identified on MRI and histopathological evidence of previous hemorrhage, most commonly in the form of hemosiderin-laden macrophages. Eleven lesions (12.9\%) in our review were noted to contain erythrocytes, which implies that not all CMBs are chronic in nature.

Recently, De Reuck et al. [9] published a study determining the neuropathological correlates of CMBs on postmortem brain sections from 20 Alzheimer patients using 7-tesla MRI. They investigated 79 hemorrhages of 1-3 $\mathrm{mm}$ in diameter on gross pathology and 163 hemorrhages invisible to the naked eye $(200-500 \mu \mathrm{m})$. They showed the sensitivity and specificity of 7-tesla GRE imaging to be 100 and 50\%, respectively, for detecting hemorrhages of $1-3 \mathrm{~mm}$ diameter and 100 and $38 \%$, respec- tively, for smaller hemorrhages $(200-500 \mu \mathrm{m})$. For the larger lesions, the positive predictive value (PPV) was $96 \%$ and the negative predictive value (NPV) was $100 \%$. For lesions of 200-500 $\mu \mathrm{m}$, the PPV and NPV were 77 and $100 \%$, respectively. False positives consisted of perforating vessels filled with postmortem thrombi or iron and calcium deposits around vessels or in astrocytes. These occurred exclusively in the deep white matter, striatum and internal capsule.

None of the studies within our review were designed to calculate the sensitivity and/or specificity of MRI in detecting CMBs proven on pathology. However, extrapolating from the available data we can make a general estimation. Among the 4 studies which utilized GRE MRI there was histopathological evidence of a hemorrhage in $33 \mathrm{CMBs}$ (true positives). False positives occurred at 13 sites (18.8\%). Most of these were from the study by Fazekas et al. [3], in which no other specific pathology was found. This study imaged postmortem whole brains surrounded by air, and it has been argued that the high falsepositive rate was likely secondary to air artifacts [6]. Pathologies underlying false-positive CMBs in the other studies included pseudocalcification of a vessel [6], a microaneurysm and a distended dissected vessel [7]. Interestingly, the vascular pseudocalcification (a known CMB mimic) located in the left pallidum of case 12 was an asymmetric finding that did not appear hyperdense on computed tomography (CT) imaging. This lesion would thus be graded as a 'definite' [10] CMB or could possibly be graded as a 'certain' [11] one, according to the currently available $\mathrm{CMB}$ rating scales. In view of the above and the frequent occurrence of calcification/mineralization within this region, we propose that unilateral pallidal lesions otherwise fulfilling the definition of a CMB should be graded as either 'possible' [10] or 'uncertain' [11] CMBs irrespective of absent hyperdensity on CT.

False negatives were only commented on in the study by Fazekas et al. [3], in which 20 MRI-negative hemosiderin deposits were isolated, 8 of which were in 2 patients who were completely lacking CMBs on MRI. Thus, exclusively in that study, we can estimate the sensitivity of CMBs on 1.5-tesla GRE MRI (TR/TE: $550-650 / 15 \mathrm{~ms}$, flip angle $\left.25^{\circ}\right)$ as $51.2 \%[21 /(21+20)]$. This number is arguably an overestimation, given the lack of proper methodology to isolate false-negative lesions. Without any true-negative values we are unable to estimate the specificity. However, we can estimate the PPV as $61.8 \%$ $[21 /(21+13)]$. The aforementioned discussion regarding false-positive lesions in this study would imply that this might be an underestimation. 
Assuming that the 7 cavitary lesions in the study by Schrag et al. [7] using 3-tesla SWI represent tissue necrosis secondary to hemorrhage, there were only 2 false positives within the $38 \mathrm{CMBs}$ visualized. The PPV in this study can thus be estimated at $94.7 \%[36 /(36+2)]$. This higher PPV in comparison to that of Fazekas et al. [3] is potentially a reflection of the minimization of air artifacts by embedding formalin-fixed brain slices in blocks of $4 \%$ agarose gel. The minimization of air artifacts noted by De Reuck et al. [9] when brain sections were submerged in physiological serum would support this. Schrag et al. [7] did not comment on false negatives or provide enough information to allow for other calculations.

In keeping with previous studies, lipofibrohyalinosis and cerebral amyloid angiopathy were the dominant vascular changes associated with CMBs [12-15]. However, CMBs have been documented at the capillary level independently of the above [16]. In those with documented cerebral amyloid angiopathy, CMBs were more frequently found in the cortico-subcortical regions, as noted elsewhere $[17,18]$. Microaneurysm formation has also previously been encountered in the vicinity of hemosiderin deposition [19-21]. The patient with moyamoya disease displayed disruption of the internal elastic lamina, which would support a different underlying etiology accounting for the $21.2 \%$ prevalence of CMBs in this disease population [22-24].

The notion that the presence of lacunar infarcts and white matter disease (WMD) increases a patient's risk of ICH is supported by the varying degrees of tissue rarefaction, gliosis and lacunar infarction that have been found in patients with microbleeds $[12,13,22,25-29]$. Moreover, it seems that CMBs are often associated with a degree of surrounding tissue necrosis, which would concur with the growing literature refuting their presumed asymptomatic nature [30-35].

A 'blooming effect' was noted in two studies with contrasting findings. The discrepancy is likely a function of the different imaging parameters used. Lengthening the TE or decreasing the flip angle is known to increase the size of CMBs [6]. Accordingly, in the study by Schrag et al. [7], who found a significant 'blooming effect', they used a TE of $20 \mathrm{~ms}$ and flip angle of $15^{\circ}$, in contrast to that by Tatsumi et al. [6] (TE $17 \mathrm{~ms}$ and flip angle $20^{\circ}$ ), who did not find any significant 'blooming effect'. De Reuck et al. [9] observed that the 'blooming effect' on 7-tesla GRE MRI was halved (from a magnitude of 5 to 2.5) by submerging the brain sections in physiological serum. Whether the different imaging media in the above stud- ies (water [6] vs. agarose gel [7]) influenced their respective observations is uncertain.

Unfortunately, the methodology of the literature on CMBs is generally inadequate [22], and the studies included in this review are no exception. Small sample sizes, unblinded rating and histopathological analysis of CMBs, absence of proper methodology to determine sensitivity and specificity, and the heterogeneity of tissue preparation, imaging parameters, patient demographics and level of individual case detail in these studies limit the scope of analysis and conclusions derived from our review.

However, these studies have demonstrated that the association between CMBs and pathologically proven microbleeds and surrounding vascular fragility, although strong and in keeping with previously reported studies, is not absolute. Accordingly, further histopathological studies with appropriate sample sizes and systematic methodologies are required to further characterize and validate these observations. A better understanding of the underlying pathology of CMBs could then guide the design of future research into their clinical relevance and implications.

\section{Appendix}

Search Strategy

A search of MEDLINE, Embase and the Cochrane Central Register of Controlled Trials with no date or language limitations was conducted in June 2010. Broad search terms were used as follows:

- microbleed

- microhaemorrhage

- microhemorrhage

(1 or 2 or 3 ).

The same search was applied to conference abstract databases from the International Stroke Conference, the European Stroke Conference and the American Academy of Neurology Annual Meeting from 2008 to 2010 to identify unpublished studies. Moreover, the references of the included trials and recent review articles were checked for additional studies.

A flow diagram of our literature search and study selection is shown in figure 1 .

References

1 Gouw AA, Seewann A, van der Flier WM, Barkhof F, Rozemuller AM, Scheltens P, Geurts JJ: Heterogeneity of small vessel disease: a systematic review of MRI and histopathology correlations. J Neurol Neurosurg Psychiatry 2011;82:126-135.

-2 Deville WL, Buntinx F, Bouter LM, Montori VM, de Vet HC, van der Windt DA, Bezemer PD: Conducting systematic reviews of diagnostic studies: didactic guidelines. BMC Med Res Methodol 2002;2:9. 
3 Fazekas F, Kleinert R, Roob G, Kleinert G, Kapeller P, Schmidt R, Hartung HP: Histopathologic analysis of foci of signal loss on gradient-echo $\mathrm{T} 2 *$-weighted MR images in patients with spontaneous intracerebral hemorrhage: evidence of microangiopathyrelated microbleeds. AJNR Am J Neuroradiol 1999;20:637-642.

4 Tanaka A, Ueno Y, Nakayama Y, Takano K, Takebayashi S: Small chronic hemorrhages and ischemic lesions in association with spontaneous intracerebral hematomas. Stroke 1999;30:1637-1642.

5 Kikuta K, Takagi Y, Nozaki K, Okada T, Hashimoto N: Histological analysis of microbleed after surgical resection in a patient with moyamoya disease. Neurol Med Chir (Tokyo) 2007;47:564-567.

6 Tatsumi S, Shinohara M, Yamamoto T: Direct comparison of histology of microbleeds with postmortem MR images: a case report Cerebrovasc Dis 2008;26:142-146.

7 Schrag M, McAuley G, Pomakian J, Jiffry A, Tung S, Mueller C, Vinters HV, Haacke EM, Holshouser B, Kido D, Kirsch WM: Correlation of hypointensities in susceptibilityweighted images to tissue histology in dementia patients with cerebral amyloid angiopathy: a postmortem MRI study. Acta Neuropathol 2009, E-pub ahead of print.

$\checkmark 8$ Fazekas F, Kleinert R, Offenbacher H, Payer F, Schmidt R, Kleinert G, Radner H, Lechner $\mathrm{H}$ : The morphologic correlate of incidental punctate white matter hyperintensities on MR images. AJNR Am J Neuroradiol 1991; 12:915-921.

$\checkmark 9$ De Reuck J, Auger F, Cordonnier C, Deramecourt V, Durieux N, Pasquier F, Bordet R, Maurage CA, Leys D: Comparison of 7.0-T $\mathrm{T}_{2}{ }^{*}$-magnetic resonance imaging of cerebral bleeds in post-mortem brain sections of Alzheimer patients with their neuropathological correlates. Cerebrovasc Dis 2011;31:511517.

10 Gregoire SM, Chaudhary UJ, Brown MM, Yousry TA, Kallis C, Jager HR, Werring DJ: The Microbleed Anatomical Rating Scale (MARS): reliability of a tool to map brain microbleeds. Neurology 2009;73:1759-1766.

-11 Cordonnier C, Potter GM, Jackson CA, Doubal F, Keir S, Sudlow CL, Wardlaw JM, AlShahi Salman R: Improving interrater agreement about brain microbleeds: development of the Brain Observer MicroBleed Scale (BOMBS). Stroke 2009;40:94-99.
2 Fisher CM: The arterial lesions underlying lacunes. Acta Neuropathol 1968;12:1-15.

13 Fisher CM: Pathological observations in hypertensive cerebral hemorrhage. J Neuropathol Exp Neurol 1971;30:536-550.

14 Okazaki H, Reagan TJ, Campbell RJ: Clinicopathologic studies of primary cerebral amyloid angiopathy. Mayo Clin Proc 1979; $54: 22-31$.

15 Ishii N, Nishihara Y, Horie A: Amyloid angiopathy and lobar cerebral haemorrhage. J Neurol Neurosurg Psychiatry 1984;47:12031210.

16 Fisher M, French S, Ji P, Kim RC: Cerebral microbleeds in the elderly: a pathological analysis. Stroke 2010;41:2782-2785.

17 Greenberg SM, Finklestein SP, Schaefer PW: Petechial hemorrhages accompanying lobar hemorrhage: detection by gradient-echo MRI. Neurology 1996;46:1751-1754.

18 van Rooden S, van der Grond J, van den Boom R, Haan J, Linn J, Greenberg SM, van Buchem MA: Descriptive analysis of the Boston criteria applied to a Dutch-type cerebral amyloid angiopathy population. Stroke 2009;40:3022-3027.

19 Cole FM, Yates PO: The occurrence and significance of intracerebral micro-aneurysms. J Pathol Bacteriol 1967;93:393-411.

-20 Fisher CM: Cerebral miliary aneurysms in hypertension. Am J Pathol 1972;66:313-330.

-21 Benhaiem-Sigaux N, Gherardi R, Salama J, Gray F, Amouroux J, Poirier J: Thrombosis of a saccular microaneurysm causing cerebral (pontine) lacunae. Acta Neuropathol 1986;69:332-336.

22 Cordonnier C, Al-Shahi Salman R, Wardlaw J: Spontaneous brain microbleeds: systematic review, subgroup analyses and standards for study design and reporting. Brain 2007; 130:1988-2003.

23 Fukui M, Kono S, Sueishi K, Ikezaki K: Moyamoya disease. Neuropathology 2000; 20(suppl):S61-S64.

24 Takagi Y, Kikuta K, Nozaki K, Hashimoto N: Histological features of middle cerebral arteries from patients treated for Moyamoya disease. Neurol Med Chir (Tokyo) 2007;47: $1-4$.

25 Inzitari D, Giordano GP, Ancona AL, Pracucci G, Mascalchi M, Amaducci L: Leukoaraiosis, intracerebral hemorrhage, and arterial hypertension. Stroke 1990;21:14191423.
26 Selekler K, Erzen C: Leukoaraiosis and intracerebral hematoma. Stroke 1989;20:10161020

27 Ovbiagele B, Saver JL, Sanossian N, Salamon N, Villablanca P, Alger JR, Razinia T, Kim D, Liebeskind DS: Predictors of cerebral microbleeds in acute ischemic stroke and TIA patients. Cerebrovasc Dis 2006;22:378-383.

$>28$ van Es AC, van der Grond J, de Craen AJ, Admiraal-Behloul F, Blauw GJ, van Buchem MA: Risk factors for cerebral microbleeds in the elderly. Cerebrovasc Dis 2008;26:397403.

29 Maia LF, Vasconcelos C, Seixas S, Magalhaes $\mathrm{R}$, Correia M: Lobar brain hemorrhages and white matter changes: clinical, radiological and laboratorial profiles. Cerebrovasc Dis 2006;22:155-161.

>30 Werring DJ, Frazer DW, Coward LJ, Losseff NA, Watt H, Cipolotti L, Brown MM, Jager HR: Cognitive dysfunction in patients with cerebral microbleeds on T2*-weighted gradient-echo MRI. Brain 2004;127:22652275

>31 Viswanathan A, Guichard JP, Gschwendtner A, Buffon F, Cumurcuic R, Boutron C, Vicaut E, Holtmannspotter M, Pachai C, Bousser MG, Dichgans M, Chabriat H: Blood pressure and haemoglobin Alc are associated with microhaemorrhage in CADASIL: a two-centre cohort study. Brain 2006;129: 2375-2383.

32 Watanabe A, Kobashi T: Lateral gaze disturbance due to cerebral microbleed in the medial lemniscus in the mid-pontine region: a case report. Neuroradiology 2005;47:908911.

33 de Laat KF, van den Berg HA, van Norden AG, Gons RA, Olde Rikkert MG, de Leeuw FE: Microbleeds are independently related to gait disturbances in elderly individuals with cerebral small vessel disease. Stroke 2011;42: 494-497.

34 Tang WK, Chen YK, Lu J, Ahuja AT, Chu WC, Mok VC, Ungvari GS, Xiang YT, Wong KS: Cerebral microbleeds and quality of life in acute ischemic stroke. Neurol Sci 2011;32: 449-454.

-35 Altmann-Schneider I, Trompet S, de Craen AJ, van Es AC, Jukema JW, Stott DJ, Sattar N, Westendorp RG, van Buchem MA, van der Grond J: Cerebral microbleeds are predictive of mortality in the elderly. Stroke 2011;42: 638-644. 